\title{
LA EDUCACIÓN MEDIATIZADA. DISTANCIAS Y APROXIMACIONES CONCEPTUALES EN LAS METODOLOGÍAS DE MEDIATIZACIÓN DEL CONOCIMIENTO
}

\author{
Diego Leandro Marín Ossa *
}

\begin{abstract}
RESUMO
Este artigo descreve o progresso de uma investigação iniciada em 2013, com o grupo de pesquisa EduMedia-3, da Escola de Espanhol e Comunicação Audiovisual da Universidade Tecnológica de Pereira, com o nome de Educación Mediatizada (Educação Midiática). O autor apresenta algumas abordagens conceituais cujas contribuições são orientadas para problematizar as metodologias utilizadas por professores e alunos na narrativa e estadiamento do conhecimento, na produção de textos e discursos dos saberes que são aprendidos e transmitidos na educação formal, não-formal e informal, e na educação presencial e a distância. Primeiro é abordada a essência da educação midiática; em seguida é problematizado o conceito de produção midiática em relação aos meios de comunicação e das TIC; depois são apresentadas algumas ideias de autores que abordam o conceito de diferentes ângulos. Em seguida são definidas as diferenças entre mediado e mediar, e, posteriormente, são apresentados os avanços relacionados com as ideias de mediadores, mídia e mediação, especialmente a mediação pedagógica no contexto da educação midiática. E, finalmente, é descrito qual é o foco de investigação de EduMedia-3, bem como a metodologia de pesquisa, que inicialmente envolveu um estudo teórico, sistematização de informações em um arquivo de documento, a encenação de uma história como pretexto para explorar a aprendizagem pela descoberta, e registro de resultados através de documentos em cada sessão, fotografias, vídeos, programas de rádio e de sites para espalhar alguns progressos, o que resultou em palestras, trabalhos de graduação e no presente artigo. Palavras-chave: Educação midiática. Mediadores. Mídia. Mediação pedagógica.
\end{abstract}

\section{RESUMEN}

En este artículo se presenta el avance de una investigación iniciada en el año 2013 con el semillero Edumedia-3, en la Escuela de español y comunicación audiovisual de la Universidad Tecnológica de Pereira, bajo el nombre de educación mediatizada. El autor presenta algunas aproximaciones conceptuales cuyos aportes están orientados a problematizar las metodologías usadas por docentes y estudiantes, en la narración y escenificación del conocimiento, en la producción de los textos y discursos de los saberes que se aprenden y se transmiten en la educación formal, no - formal e informal, y en la educación presencial y a distancia. Primero se define la educación mediatizada, después se problematiza el concepto de mediatización con relación a los medios de

\footnotetext{
* Magister en comunicación educativa. Director del Semillero de investigación EduMedia-3, línea de investigación en Educación mediatizada. Profesor asociado en la Escuela de español y comunicación audiovisual, Facultad de Ciencias de la Educación de la Universidad Tecnológica de Pereira, Colombia. leandro73@utp.edu.co
} 
comunicación y las TIC, luego se exponen algunas ideas de autores que abordan el concepto desde diferentes ángulos. Seguido a esto se establecen distinciones entre lo mediado y lo mediato, y finalmente se presentan avances relacionados con las ideas de mediadores, medios y mediaciones, en especial la mediación pedagógica en el contexto de la educación mediatizada. Y finalmente se explica en qué consiste el semillero de investigación Edumedia-3, así como la metodología de investigación, que ha implicado inicialmente un estudio teórico, la sistematización de información en un archivo documental, la puesta en escena de un relato como pretexto para explorar el aprendizaje por descubrimiento, y el registro de los hallazgos a través de actas en cada sesión, fotografías, videos, página web y programas de radio para difundir algunos avances, lo que ha dado como resultado ponencias, trabajos de grado y el presente artículo.

Palabras-clave: Educación mediatizada. Mediadores. Medios. Mediación pedagógica.

\section{ABSTRACT \\ MEDIATED EDUCATION. CONCEPTUALDISTANCES AND PROXIMITIES IN METHODOLOGIES FOR MEDIATION OF KNOWLEDGE}

This article describes the progress of an investigation launched in 2013 with EduMedia-3, undertaken at the Technological University of Pereira's School of Spanish and Audiovisual Communication, under the category of mediated education. The author presents some conceptual approaches whose contributions are oriented to problematize the methodologies used by teachers and students in the narration and staging of knowledge in the production of educational texts and discourses that are learned and transmitted in formal, non-formal, and informal education, both in the classroom and via distance education. First of all, the mediated education is defined afterward the mediated concept is made problematic related to the media and the ICT. Then, some ideas of authors who address the concept from different perspectives are exposed. At that time, the distinctions between the mediated and mediate are established. Lastly, the advances related to the ideas of the mediators, media and mediations are presented specially the pedagogical mediation in the mediated education context. To conclude, it is explained what the Edumedia-3 semillero of investigation consists, and the research methodology which has involve at the beginning a theoretical study, the systematization of data in a documental file, the staging of a story as a pretext for exploring the learning by discovery, and the findings' register through the agreements, photography, videos, web page and radio program in each session to spread some advances. It has given as a resulted presentations, dissertations and the present article.

Keywords: Mediated education. Mediators. Media. Pedagogical mediation.

\section{Introducción}

Llamo Educación mediatizada a las maneras o metodologías usadas por los educadores y los estudiantes para mediatizar el conocimiento, tanto en la educación formal, como en la no formal e informal, en ambientes educativos diseñados para las aulas de clase que requieran de la presencia corporal y de la comunicación cara a cara, en aulas virtuales que requieran o no de 
presencias corporales o verbales digitalizadas (IE), en lugares de encuentro de organizaciones sociales, culturales y educativas (ONG y ORG), o en otros escenarios del conocimiento como los medios de comunicación educativa y cultural, ya sean privados, públicos o mixtos.

Dicho proceso de representación del conocimiento orientado a la formación, implica para docentes y estudiantes los usos de los mediadores de la educación: signos, códigos y lenguajes, expresados a través de textos y discursos, en los escenarios ya descritos.

También requiere de los medios para la educación: los cuerpos, las voces, los cuadernos de apuntes, los tableros, las pantallas (dispositivos móviles o fijos, monitores y reproductores de televisión, video y audio, video proyectores, computadores), y los usos, la apropiación y elaboración de fotografía, cartel, cómic, cine, programas de radio y televisión, videos y multimedia. Pero además el proceso implica las mediaciones (MARTÍN, 2008) cognitivas, estructurales, tecnológicas y culturales, y de manera especial la mediación pedagógica (GUTIÉRREZ; PRIETO, 2007).

En el tiempo que llevo investigando y teorizando la Educación mediatizada como metodología (desde agosto del año 2013 hasta la fecha), me he dado cuenta de la importancia que tiene la teoría del relato (DUCH; CHILLÓN, 2012), como el recurso que estructura el proceso de mediatización del conocimiento. El relato del conocimiento en el que hay narraciones y argumentaciones (BRUNER, 2010) que se cuentan o se ponen en escena entre docentes y estudiantes.

He aprendido que los relatos de las Ciencias Naturales, de las Ciencias Sociales y Humanas, comparten elementos morfológicos, estructurales y funcionales con la literatura oral y escrita, con el teatro y el performance. Y que los docentes y estudiantes como relatores, cumplen con los roles de narradores e incluso de personajes que dialogan entre sí, en las estrategias que usamos como espacie para transmitir ideas más o menos longevas, fieles en el copiado, y con capacidad de réplica (DAWKINS, 2014), a través de algo que podría llamarse la mémesis de la diégesis educativa, en la mediatización de la cultura (THOMPSON, 1998).

\section{Modos y modas, formas y fórmulas}

Cuando se habla de sociedad mediatizada (DE MORAES, 2007), procesos de enseñanza y aprendizaje mediados por TIC, y otras expresiones similares en la ola de la sociedad y la economía del conocimiento, se asocia esto con la presencia y el uso de tecnologías y medios de comunicación en la educación. Pero además se asume que cualquier situación educativa en la que se usen tecnologías y medios ya es un hecho mediado o mediatizado. Esto nos lleva a plantear varios interrogantes.

Algunas preguntas que han surgido en el curso de esta investigación se pueden plantear de la siguiente manera: ¿Cuándo hablamos de algo mediatizado a qué nos referimos?, o ¿qué se entiende por educación mediatizada?, ¿acaso existe un tipo de educación que no sea mediatizada?, ¿en la sociedad contemporánea puede imaginarse algo que no sea mediatizado, como por ejemplo la educación?

Al parecer persiste la idea que la inserción de las TIC y de los medios es suficiente e imprescindible para garantizar la innovación comunicativa y educativa, y que su presencia en las prácticas educativas por parte de los docentes, los estudiantes y las instituciones, es indicio de evolución en una sociedad desarrollada.

De ser así, una educación mediatizada sería aquella en la que cada estudiante posee dispositivos móviles, los docentes acceden a salas llenas de ordenadores de última generación con acceso a internet, en cada salón de clases hay televisores y video proyectores instalados en techos y paredes, y en general existe una infraestructura de telecomunicaciones al servicio de la educación, con lo cual bastaría la dotación y la alfabetización tecnológica para garantizar el aprendizaje, lo que nos lleva a reducir de alguna manera la brecha del acceso a la tecnología, pero no la brecha de la alfabetización tecnológica y de la educación para los medios de comunicación, menos aún la brecha de los usos educativos de los medios y las TIC.

Si compartimos esa idea entonces seguimos confundiendo los modos con las modas y las formas con las fórmulas. Me explico.

Por una parte los modos de concebir y de hacer en la construcción del conocimiento, requieren comprender y apropiar los atributos y característi- 
cas de los medios para la educación, es decir su naturaleza ontológica, epistemológica y pragmática.

Y por otra parte las modas son apenas imágenes estereotipadas que nos hacemos, de los usos instrumentales de los medios cuando limitamos su uso para dar instrucciones, sin servirnos de ellos para educar.

De allí que en la praxis educativa, en lugar de emerger las formas o las metodologías de educación a partir de una concepción profunda de los medios en la educación, surgen las fórmulas que se copian fuera del contexto del que nacen, y con frecuencia esto se hace bajo el rótulo de innovación educativa, cuando no es que se presentan dichas fórmulas como paradigmas de una educación novedosa que sería opuesta a una educación tradicional.

Tal situación me lleva a proponer una reflexión orientada a la comprensión y explicación de la educación mediatizada, como aquellas metodologías en las que no son los medios los protagonistas aunque en muchos casos sean de utilidad, sino las relaciones entre docentes y estudiantes en el proceso de mediatización del conocimiento, en el que los sistemas simbólicos son los que prevalecen como fundamento de cualquier medio, mediador y mediación utilizados para educar.

Dicha relación mediatizada en el contexto de la Tecnología Educativa, la Comunicación educativa y la Educomunicación, gracias a Francisco Gutiérrez y a Daniel Prieto Castillo (2007) tiene nombre: La mediación pedagógica.

Ahora continuaré la reflexión dando respuesta a una pregunta relacionada con el título de este texto: ¿Qué significa mediatizar?

\section{El verbo mediatizar y el adjetivo mediatizado (a)}

El verbo mediatizar posee dos significados: ${ }^{1}$ Uno: Intervenir dificultando o impidiendo la libertad de acción de una persona o institución en el ejercicio de sus actividades o funciones. Dos: Privar al Gobierno de un Estado de la autoridad suprema, que pasa a otro Estado, pero conservando aquel la soberanía nominal.

De allí que al intervenir dificultando o impi-

1 Según el diccionario de la Real Academia Española (2015a). diendo la acción de otros, ya sean personas o instituciones, o privando al gobierno de un Estado de la autoridad que ejerce y pasándola a otro Estado, el acto de mediatizar implica afectar las libertades individuales y colectivas.

Al parecer ambas definiciones provienen de la teoría del poder, la geopolítica y la política, y no tienen que ver con la educación o con las teorías de los medios y de las mediaciones.

Sin embargo una idea de Eliseo Verón (2001, p. 15), lleva a pensar que no sólo existen relaciones estrechas entre educación, poder y medios sino además entre el acto de mediatizar y la educación, cuando afirma que una "sociedad en vías de mediatización es aquella donde el funcionamiento de las instituciones, de las prácticas, de los conflictos, de la cultura, comienza a estructurarse en relación directa con la existencia de los medios". Es lo que John B. Thompson (2002, p. 12) llama mediatización de la cultura moderna, fenómeno que define como el "proceso general por el cual la transmisión de formas simbólicas llega a estar cada vez más mediada por los aparatos técnicos e institucionales de las industrias de los medios de comunicación".

Ahora bien, en el contexto estrictamente educativo Jerome S. Bruner y David R. Olson (1973, p. 26), consideran que el aprendizaje se puede propiciar por experiencia directa y por experiencia mediatizada, al respecto afirman que: "Otra posibilidad de prescindir de la experiencia directa consiste en utilizar una información codificada, es decir, transmitirla por un tercer medio: la palabra oral o escrita, una película, un diagrama, etc. Este aprendizaje por experiencia mediatizada es el que reemplaza más fácilmente a la experiencia directa en la enseñanza tradicional. Vygotsky (1962) y Bruner et al (1966) han subrayado el lugar ocupado por el lenguaje, el cual representa el medio por excelencia para aprender y enseñar fuera del contexto, en una situación en la que la acción misma y sus consecuencias contingentes no aparecen inmediatamente. El lenguaje representa, por tanto, el mejor medio de adquirir conocimientos cuya utilidad no se puede comprobar mediante una acción determinada. Es el instrumento que se presta más directamente a la organización de los conocimientos según las reglas del pensamiento abstracto. 
Disponemos, pues, de tres modos de experiencia que corresponden, grosso modo, a las tres formas de representación definidas por Bruner (1966): activa, icónica y simbólica; la primera concierne a la acción directa, la segunda a los modelos y la tercera a los sistemas de símbolos". Cabe resaltar el lugar que se atribuye al lenguaje como el medio e instrumento, no sólo para adquirir el conocimiento, también para organizarlo con la opción de representarlo, aún en ausencia de una experiecia directa con los objetos de aprendizaje. Es el lenguaje el medio que permite mediatizar el conocimiento y hace posible que se le de forma a complejos sistemas de pensamiento.

Y desde otro ángulo también cabe recordar una de las ideas de Paulo Freire (2014, p. 96), más sugestivas, conocidas y difundidas en numerosos trabajos académicos y de investigación. En su momento Freire dijo que: "Já agora ninguém educa ninguém, como tampouco ninguém se educa a si mesmo: os homens se educam em comunhão, mediatizados pelo mundo". ${ }^{2}$ Entonces a partir de lo expresado por dicho pedagogo ¿qué relaciones se pueden establecer con la educación mediatizada?

Considero que por una parte podemos resaltar la naturaleza dialéctica de esta idea, pues cuando Freire (2008, p. 92) dice que "nadie educa a nadie, como tampoco nadie se educa a sí mismo", se puede interpretar que lo que pretendía era cuestionar la relación hegemónica y unidireccional entre docentes y estudiantes, como también la actitud dócil de los aprendices, pues al señalar que "los hombres se educan en comunión", hace el énfasis en la puesta en común, esto es: el debate, la discusión y el diálogo.

Y al decir "mediatizados por el mundo", de alguna manera se infiere que la experiencia que viven las personas, juega un papel decisivo en la manera como adquieren conocimiento, y cómo estructuran sus conocimientos, pero en la perspectiva de Freire, esta experiencia con el mundo es dinámica y dialéctica, y enfrenta a docentes y estudiantes a los

2 "Ahora nadie educa a nadie, como tampoco nadie se educa a sí mismo: los hombres se educan en comunión, mediatizados por el mundo" (FREIRE, 2008, p. 92). Prefiero citarlo en portugués pues algunas ediciones en español en lugar de decir "mediatizados por el mundo", dicen: "y el mundo es el mediador" (edición de Siglo XXI en la que el traductor es Jorge Mellado), a mi parecer se trata de dos ideas diferentes. avatares de la historia, de las relaciones políticas y económicas que en gran parte definen sus maneras de saber. Al respecto advierten Gutiérrez y Prieto (2007, p. 14):

Una universidad anclada en el traspaso de conocimientos termina por perder su sentido, el de la formación de seres humanos, que no se logra con la acumulación de datos sino por la pasión por la comunicación, por la relación humana, por la aventura de realizarse como persona, a partir de la construcción de conocimientos, de la creatividad, de la investigación y del intercambio de experiencias.

Ahora bien, es importante decir que en la lengua portuguesa como en la lengua castellana, el significado del verbo mediatizar se asocia con los medios de comunicación y con el poder en dos sentidos: Uno: Fazer ou fazer-se conhecer pelos meios de comunicação social ou por qualquer suporte de difusão de informação. Dos: Fazer com que um príncipe, um Estado, deixem de depender imediatamente do poder supremo.

Y el adjetivo mediatizado significa: Uno: que se mediatizou. Dos: que é conhecido ou divulgado pelos meios de comunicação social ou por qualquer suporte de difusão de informação. Tres: designativo de país unido a outro mais poderoso.

\section{Naturaleza de la educación mediatizada (lo mediado y lo mediato)}

Pero ¿cuál es la naturaleza de la educación mediatizada?, o dicho de otro modo: ¿cuáles son los atributos y características de la educación mediatizada que permiten al docente y a los estudiantes comprender y poner en práctica sus posibilidades educativas?

Para responder estos interrogantes, es preciso tener en cuenta que en el contexto de lo que denomina una "democracia audiovisual evolucionada", Verón (1998, p. 124), identifica en las sociedades postindustriales: "Una sociedad en vías de mediatización (distinguible de la sociedad mediática del período anterior, es decir, una sociedad en que poco a poco se implantan tecnologías de comunicación en la trama social) no por esto es una sociedad dominada por una sola forma estructurante", y continúa diciendo: 
La mediatización opera a través de diversos mecanismos según los sectores de la práctica social que interese, y produce en cada sector distintas consecuencias. Dicho de otro modo: una sociedad mediatizada es más compleja que las que le han precedido. A pesar de lo que se diga, la publicidad, el discurso político, el discurso informativo, el discurso científico, etc., resultan de condiciones de producción y de reconocimiento diferentes, específicas en cada caso. (VERÓN, 1998, p. 124).

Aquí se refiere a la semiosis social (VERÓN, 2014), en la producción de los diferentes discursos, a los que agregaremos los educativos.

Digamos con Gutiérrez y Prieto (2007, p. 14), que:

Uno de los problemas más graves de la educación universitaria en nuestros países es la presencia de un discurso educativo no mediado pedagógicamente, tanto en la relación presencial como en los materiales utilizados.

Con relación a lo anterior es oportuno decir que Verón (1998, p. 125), afirma:

En cada práctica discursiva, la mediatización ha implicado la incorporación progresiva de nuevos registros significativos. En su historia, de una manera muy esquemática, la mediatización influyó primero en la escritura, con la prensa masiva (el orden de lo simbólico, en la terminología de Peirce); a continuación se fue haciendo cargo del universo figurativo de la representación, con la fotografía y el cine (el orden de lo icónico, siempre según Peirce), y finalmente se apoderó del registro del contacto, en forma parcial en primer lugar - con la radio, y luego en forma plena mediante la televisión para el público en general (el orden de lo indicial peirceano).

Y advierte: "La incorporación de un nuevo registro significativo no ha implicado, claro está, la anulación de los anteriores" (VERÓN, 1998, p. 125).

El argumento de Verón permite comprender que la sociedad mediatizada, adquiere esta cualidad a través de procesos de transformación sígnica que hoy posibilitan la coexistencia de diversos sistemas simbólicos, que usamos para comunicarnos, para representar y como vehículos de cognición. Pero además en el contexto educativo y cultural, exige de nosotros la elaboración de formas de comunicación y de educación acordes con dicha complejidad, y en ese sentido uno de los retos que esto implica son las distancias y las aproximaciones metodológicas que hay que tener presentes en el diseño, la implementación y la evaluación.

\section{Al respecto haré una distinción entre lo mediado y lo mediato.}

En este momento vale preguntarse si ¿acaso existe una sutil diferencia semántica entre la idea de educación mediada y la idea de educación mediatizada?, y si ¿será que el uso indiferente de los dos términos, dio origen a una contradicción fundamental expresada en las prácticas educativas, cuando se confunde la educación mediada con la educación mediatizada y se piensa que son la misma cosa?

De allí que se necesita elaborar la distinción entre lo mediado y lo mediato. Y esta distinción semántica es necesaria, en la medida que escudriñar la naturaleza del pensamiento y del lenguaje ayuda a distinguir el fenómeno de mediatización, no solo como fenómeno lingüístico, semiótico y social, sino también como un fenómeno educativo, mediático, político, cultural e histórico.

Más aún cuando al opinar sobre estos temas, nos acostumbramos a usar de manera indiferente términos como mediar y mediatizar, o mediado y mediatizado, como si se hablara de la misma cosa.

Dice la Real Academia Española (2015b) que mediatizar viene de mediato e izar, y mediato significa que en tiempo, lugar o grado (algo) está próximo a una cosa, mediando otra entre las dos, "como el nieto respecto del abuelo". Mientras que mediado viene de mediar, y significa: Que contiene la mitad, poco más o menos, de su cabida. "La vasija está mediada". Por lo cual tras este sencillo razonamiento se puede afirmar que lo mediato se asocia con la distancia, ${ }^{3}$ (más o menos cerca o más o menos lejos), mientras que lo mediado se asocia con la cantidad, (más o menos lleno o más o menos vacío). Lo que a mi parecer genera primero que todo el vínculo parental en el ejemplo del nieto y el abuelo, como también genera el vínculo provisional en el caso de la vasija, aún sin saber en dicho ejemplo qué es lo que esta contiene. Si el contenido es líquido o sólido, o si es producto

3 Se dice: ¡de inmediato!, o a veces ¡en el término de la distancia! 
de otras implicaciones o de acciones que lleven a concluir que: "alguien tomó un poco de la vasija", "es todo lo que queda en ella", o "si lo que tienes allí no alcanza para llenarte, entonces te sirvo más". ${ }^{4}$

En fin, el ejercicio aquí es producto de una especulación metafórica ${ }^{5}$ que a veces es útil para desentrañar sentidos y ejemplificar razonamientos.

El otro vínculo que encuentro es, por una parte geométrico, por aquello de la distancia implicada en lo mediato y por lo tanto en la acción de mediatizar; y por otra parte el vínculo matemático, por aquello de la cantidad implicada en lo mediado y por lo tanto en la acción de mediar.

Es decir que lo mediado se diferencia de lo mediato, y se concluye que mediar no significa lo mismo que mediatizar, así como mediado no significa lo mismo que mediatizado.

Sin embargo hasta aquí no encontramos la relación con los medios de comunicación, lo que llevaría a pensar que una educación mediada o una educación mediatizada se puede generar en ausencia de estos, pero no en ausencia de la experiencia directa y mucho menos prescinde de la experiencia mediatizada por medio del lenguaje. Aquí la distinción es fundamental, son los modelos y los sistemas simbólicos los que hacen de la educación un proceso mediado como también uno mediatizado.

\section{Lo que de paso nos lleva a concluir:}

Primero. Que mediar la educación es una acción que se asocia con los temas, los contenidos y los contenedores (la vasija está mediada), mientras que mediatizar la educación, es una acción que se asocia con los procesos de mediación entre dos (o más) elementos, es decir, mediatizar la proximidad a una cosa (que puede ser la proximidad entre su-

\footnotetext{
4 Imaginemos al docente y a los estudiantes haciendo estas consideraciones en el contexto educativo. Más allá de las metáforas imaginemos situaciones concretas, relacionemos lo mediato con la distancia que experimentan ambos con relación a los objetos de conocimiento, y como los procesos aumentan y reducen dicha distancia. Imaginemos también que todos consideran lo mediado como la actividad de llenado de mentes vacías, o como la vasija a medio llenar, esto tiene otras implicaciones con relación al desarrollo de temas y de contenidos.

5 Esto me recuerda la idea de Steven Pinker, lo que él denomina cadena de metáforas, en el capítulo 5 titulado La metáfora de la metáfora, del libro El mundo de las palabras. Una introducción a la naturaleza humana (PINKER, 2007).
}

jetos cognoscentes y objetos de conocimiento), en términos de tiempo, lugar o grado (como el nieto respecto del abuelo). ${ }^{6}$

Con relación a esto Francisco Gutiérrez Pérez y Daniel Prieto Castillo (2007, p. 70), afirman: que en la educación "lo temático será válido en la medida que contribuya a desencadenar un proceso educativo. No interesa una información en sí misma sino una información mediada pedagógicamente".

Segundo. Que mediar y mediatizar la educación no siempre implica el uso del ordenador, del video proyector, del periódico o de cualquier otro medio de comunicación que hoy conocemos. En la educación el libro, el tablero y el cuaderno de apuntes también son medios.

Es más, en muchos casos no se requiere de estos para decir que un acto educativo se ha mediado o se ha mediatizado, basta con usar la voz y el cuerpo como medios, el espacio territorial y la distancia espacial, la gestualidad y la oralidad de los docentes y de los estudiantes para generar dichos procesos en la educación.

En este sentido Mario Kaplún (2010, p. 42), se pregunta:

¿no coincide el lector en que, al identificar comunicación sólo con medios e instrumentos, son empobrecedoramente reductores?

Por otra parte, ¿qué aporte sustancial se está introduciendo allí en lo propiamente educativo, en lo pedagógico?

Más bien pareciera tratarse de reproducir el viejo cuño del maestro omnisapiente instruyendo al alumno ignorante, sólo que mediatizado y revestido de recursos modernos y atrayentes.

Y continúa diciendo que "el diálogo entre la educación y la comunicación está lejos de haber sido hasta ahora fluido y fructífero. Lo más frecuente ha sido que la primera entendiera a la segunda en términos subsidiarios y meramente instrumentales, concibiéndola tan sólo como vehículo multiplicador y distribuidor de contenidos que ella predeter-

6 En el ejemplo tanto el nieto como el abuelo son los sujetos cognoscentes, mientras que el objeto de conocimiento es su relación, complejizada por el amor que se tienen, los diferentes puntos de vista, la diferencia de edades entre otras cosas, es decir, las mediaciones que les permite interpretar en diferentes lugares, tiempos y grados su relación. Así también podríamos elaborar un ejemplo con docentes y estudiantes. 
mina. Así, cuando en una planeación educativa se considera necesario valerse de medios de comunicación o producir materiales educativos, se recurre al técnico en comunicación (y hay que admitir que, lamentablemente, los propios profesionales de la comunicación alimentaron el equívoco y aceptaron ser vistos como suministradores de recursos técnicos envasadores de mensajes). Se fue petrificando de ese modo el doble y pertinaz malentendido: la comunicación equiparada al empleo de medios tecnológicos de transmisión y difusión y, a la vez, visualizada como mero instrumento subsidiario, percepción que la mutila y despoja de lo mucho que ella tiene para aportar a los procesos de enseñanza/ aprendizaje" (KAPLÚN, 2010, p. 42).

Por su parte Gutiérrez Pérez y Prieto Castillo (2007, p. 69), afirman que:

Resulta de fundamental importancia diferenciar con claridad un modelo pedagógico, cuyo sentido es educar, de un modelo temático, cuyo propósito es enseñar. Este último hace énfasis en los contenidos como clave de todo el proceso: se trata de traspasar información, de verificar su asimilación y de evaluar la retención por parte del estudiante. Hay sistemas educativos organizados de esta manera y docentes que sólo conciben la educación como traspaso de conocimientos.

Sin embargo y a pesar del debate en el que en ocasiones se presentan estos asuntos como antagónicos, hoy resulta tan valiosa la educación mediada como la mediatizada, cada una en su momento y en mutua correspondencia, según las intenciones educativas de los docentes y los estudiantes, y según los contextos.

De ello dependerán los mediadores, los medios y las mediaciones usadas para mediar y mediatizar el conocimiento.

\section{Mediatización del conocimiento o educación mediatizada}

\section{Recordemos que la educación mediatizada ${ }^{7}$}

7 Para mi que la educación mediatizada es una categoría que se fundamenta en tres subcategorías: los mediadores del conocimiento usados para representarlo, los medios usados para comunicarlo, y las mediaciones que sirven para explicarlo, interpretarlo y comprenderlo. Cabe decir que la educación mediatizada no se reduce al uso instrumental e instruccional de los medios en la educación, de hecho no siempre requiere de medios de comunicación masiva. Por la defino como el proceso de mediatización del conocimiento, a través de los sistemas simbólicos usados en la diégesis educativa, entendida como narración oral e icónica y en la mímesis educativa entendida como acto escénico y audiovisual, en el que están implicados los docentes y los estudiantes de manera consciente, ${ }^{8}$ los mediadores usados por ellos, es decir las variadas formas de relatar, de narrar, de argumentar, de escenificar, o sea las maneras de representar el saber a través de modelos y sistemas simbólicos. ${ }^{9}$

Para ello tanto docentes como estudiantes se sirven del lenguaje verbal, el lenguaje no-verbal, los índices, los íconos y los símbolos, ${ }^{10} \mathrm{y}$ del lenguaje audiovisual como vehículos de representación, y actúan como narradores y actores, sin más maquillajes, vestuarios y escenografías diferentes a los que ofrece la vida cotidiana dentro y fuera de las aulas de clase, ${ }^{11}$ distinguiendo entre los relatos orales, escritos y escénicos que se expresan de una manera en las artes del espectáculo (danza, música, teatro y cine, y otras formas como la pantomima,

otra parte los mediadores se entienden como recursos simbólicos como lo comprenden Lev Vygotsky o Jerome Bruner, no se trata del mediador entendido como aquellas personas que median en un conflicto (ya sean psicólogos, trabajadores sociales, sociólogos, políticos, sacerdotes o cualquier otra persona que pretenda salidas negociadas a los conflictos). Y las mediaciones se entienden en el sentido en que Manuel Martín Serrano lo explicó, o como Jesús Martín Barbero, Guillermo Orozco y Carlos Scolari lo explican en sus obras, y de manera especial la mediación pedagógica expuesta por Daniel Prieto Castillo. Por lo que se entenderá que las fuentes teóricas son: las teorías de la recepción activa, de las mediaciones, teorías culturalistas, la comunicación educativa y la educomunicación.

8 Para ello docentes y estudiantes reflexionan las maneras cómo piensan y expresan lo que conocen, indagan cómo aprenden y explican lo que conocen, exploran cómo representan el conocimiento, y en este proceso de investigación-acción educativa, adquieren la conciencia de que logos (las ideas), son mitos (relatos) y que lo real (que ya es y que ya está en el mundo) también es realidad (invención, transformación, mutación), y que la verdad cuyas fuentes de igual valor son las artes, las religiones y las ciencias, también es fruto del acuerdo entre usuarios de dicha convención. Sea o no verificable a través del método científico, resulte o no razonable desde el punto de vista filosófico, coincida o no con la fe en un dogma: la verdad cualquiera que sea su origen y sus consecuencias, es una necesidad ontológica y contingente para la especie, que periódicamente debate su pertinencia e incluso su naturaleza, ya sea para optar por la paz o por la guerra.

9 Una narración interminable según Lluís Duch y Albert Chillón, en su obra Un ser de mediaciones. Antropología de la comunicación, publicado por Heder en el año 2012.

10 Me refiero a la tricotomía del signo según Peirce, que Eco (2010) ha explicado en sus textos.

11 Idea desarrollada por Erving Goffman (2009) en su obra La presentación de la persona en la vida cotidiana. 
la declamación y el performance), y la narración y escenificación mediatizada del conocimiento, ${ }^{12}$ que aunque se sirva de dichas artes para enriquecer la multiexpresividad ${ }^{13}$ de los docentes y los estudiantes a la hora de comunicar el saber, es un proceso diferente tanto en sus medios como en sus fines.

Por otra parte en este proceso están implicados los medios: en primera instancia la voz y el cuerpo como el primer medio de comunicación audio-visual que poseemos los educadores y los estudiantes, ${ }^{14}$ además del libro, el tablero, el cuaderno de notas, el periódico, las revistas, la fotografía, el cartel, el comic, el cine, la radio, la televisión, el video y la imagen en general. ${ }^{15}$

$\mathrm{Y}$ tanto los docentes como los estudiantes utilizamos estos vehículos comunicativos como portadores de conocimiento, a través de los relatos científicos; los relatos literarios, teatrales y cinematográficos; y a través de los relatos filosóficos y mitológicos.

La riqueza textual, contextual y discursiva ${ }^{16}$ de dichos medios y relatos se expresa a través de los códigos, o sea de los complejos sistemas de signos y de lenguajes que he mencionado, y es aprovechada por los docentes y estudiantes al menos en tres sentidos:

Para hacer lecturas formales y críticas de los contenidos (leer el conocimiento en los medios ${ }^{17}$ ), es decir cómo y con qué intensiones se le da forma

12 La obra de Seymour B. Sarason es de gran utilidad para el desarrollo de esta idea. En especial su libro titulado La enseñanza como arte de representación (SARASON, 2002).

13 El concepto es de Rodrigo Argüello, y está desarrollado con amplitud en su libro Las proyecciones de Prometeo (ARGÜELLO, 2011).

14 De hecho podemos considerar que hay estudiantes y docentes que poseen habilidades y experiencia en la pintura, la escultura, el teatro, la declamación, el performance, la escritura de poesía, cuento y novela. De allí que las artes se pueden abordar como medios de expresión, como medios de comunicación e incluso como medios de representación del conocimiento.

15 La historia, la filosofía, la arqueología y la antropología de la comunicación nos han permitido identificar y caracterizar estos y otros medios, y reflexionar sus implicaciones éticas, estéticas y culturales. Podemos ver obras como De Gutemberg a Internet. Una historia social de los medios de comunicación, de Briggs y Burke (2002), o Los media y la modernidad de John Thompson (1998).

16 Aquí los aportes desde la lingüística textual, son tan valiosos como los aportes desde la sociolingüística, la pragmática del lenguaje y el postestructuralismo.

17 Leer entendiendo que se lee un texto, y que texto viene de tejido, y que la imagen también es un tejido como lo explica Barthes. al conocimiento, ${ }^{18}$

Para inducir, deducir y abducir ${ }^{19}$ un conocimiento representado en los medios (explicar y comprender el conocimiento a través de los medios), usándolos y adaptándolos a diversos contextos educativos y culturales, en los cuales lo que ya está producido adquiere valor educativo así no se haga con intensiones educativas,

En la producción de contenidos culturales y educativo ${ }^{20}$ (narrar y argumentar ${ }^{21}$ el conocimiento con los medios), usados en la educación formal, no formal e informal. ${ }^{22}$

En este sentido los docentes y estudiantes son emisores y receptores en una relación dialógica que los ubica como protagonistas del acto educativo, ${ }^{23}$ en los procesos de construcción del conocimiento, y se diferencian del periodista y el comunicador que trabaja para los medios de comunicación, pues ellos no dependen de la empresa mediática para su labor, ni para su intencionalidad formativa, aunque pueden apropiar algunas lógicas en la producción, difusión y recepción de los medios pero con fines educativos e investigativos.

Y finalmente están implicadas las mediaciones: estructurales y cognitivas, ${ }^{24}$ técnicas, culturales, las

18 Es importante tener presente que los medios ofrecen posibilidades y limitaciones epistemológicas, más allá del histórico debate originado desde el Mito de La Caverna planteado por Platón, pasando por la confrontación entre los filósofos de la Escuela de Fráncfort y los Funcionalistas. Al respecto se puede leer Las Proyecciones de Prometeo de Rodrigo Argüello Guzmán (2011).

19 Se trata de la propuesta de Peirce.

20 En la historia de relaciones entre medios y educación, cabe destacar las intenciones, limitaciones y posibilidades que ofrece la Tecnología educativa en la actualidad, la Comunicación Educativa y la Educomunicación más allá de la enseñanza instruccional, y del determinismo tecnológico.

21 Me refiero a las dos modalidades de pensamiento propuestas por Jerome Bruner (2010), en su libro Realidad mental y mundos posibles. Los actos de la imaginación que dan sentido a la experiencia.

22 Podemos pensar en las aulas de clase, en las aulas virtuales, en la educación dentro de las instituciones educativas de formación básica, media, técnica, tecnológica, superior y de postgrado, pero además en la educación a distancia, semi-presencial, y en escenarios de formación con organizaciones sociales. En estos entornos es importante la mediación pedagógica, un medio por sí mismo no posee la capacidad formativa, aunque un receptor considere que sustrae aprendizajes de algo que recepciona.

23 Me refiero a la propuesta de Kaplún, al EMIREC, a la comunicación y la educación dialógicas y enfocadas a los procesos.

24 La teoría de la mediación social propuesta por Manuel Martín Serrano, y explicada en dos de sus libros: La mediación social (MARTÍN, 2008) y La producción social de comunicación (MARTÍN, 2009), idea que luego desarrollaron en otros contextos Jesús Martín Barbero, Guillermo Orozco y Carlos Scolari. 
micro y macromediaciones y las hipermediaciones, todas ellas se han formulado con diferentes grados y niveles de complejidad, pero de manera especial la mediación pedagógica ${ }^{25}$ ubicada en el centro del proceso de mediatización del conocimiento, del cual es su protagonista.

Al respecto Gutiérrez y Prieto (2007, p. 70), afirman que:

La mediación pedagógica parte de una concepción radicalmente opuesta a los sistemas instruccionales, basados en la primacía de la enseñanza como mero traspaso de información. Entendemos por mediación pedagógica el tratamiento de contenidos y de las formas de expresión de los diferentes temas a fin de hacer posible el acto educativo dentro del horizonte de una educación concebida como participación, creatividad, expresividad y relacionalidad.

\section{Distancias y aproximaciones}

Una síntesis de las ideas más relevantes, sirve para ver las rutas de las próximas pesquisas con relación a una teoría de la educación mediatizada, fenómeno que abarca diversos escenarios y modalidades de la enseñanza y del aprendizaje.

Como parte de estas conclusiones preliminares, podemos señalar algunos aspectos que serán de utilidad para abordar de nuevo el tema, y sus múltiples aristas.

En ese orden de ideas se puede afirmar:

- Que mediar la educación es una acción que se asocia con los temas, los contenidos y los contenedores, mientras que mediatizar la educación, es una acción que se asocia con los procesos de mediación entre dos (o más) elementos, es decir, mediatizar la proximidad a una cosa (que puede ser la proximidad entre sujetos cognoscentes y objetos de conocimiento), en términos de tiempo, lugar o grado.

- Que mediar y mediatizar la educación no

25 La mediación pedagógica, de Francisco Gutiérrez Pérez y Daniel Prieto Castillo (2007), este último ha desarrollado la idea en diversos textos, conferencias, cartillas y otros materiales educativos de amplia difusión. Se puede decir que esta idea y el libro, son fruto de la investigación-acción pedagógica, como parte de la labor emprendida por estos dos educadores en Centroamérica, y de manera especial en la Universidad Rafael Landívar y en la Universidad de San Carlos en Guatemala a finales del siglo XX. siempre implica el uso del ordenador, del video proyector, del periódico o de cualquier otro medio de comunicación que hoy conocemos. En la educación el libro, el tablero y el cuaderno de apuntes también son medios.

- Además ya se ha planteado que tanto una educación presencial como una educación a distancia, sea formal, no-formal o informal requiere de una conceptualización de las metodologías para comprender la naturaleza de la educación mediatizada, de manera tal que se supere el reduccionismo que nos lleva a pensar que una educación mediada o una educación mediatizada dependen de los modernos medios de comunicación, como simples instrumentos para la transmisión de información.

- Estas metodologías tendrán que basarse en relaciones dialógicas, y en procesos que posibiliten la participación de docentes y estudiantes en el acontecimiento del saber.

- También es importante decir que el conocimiento se adquiere fruto tanto de la experiencia directa, como de la experiencia mediatizada, ya sea a partir de modelos o de complejos sistemas simbólicos, lo que sugiere que es el lenguaje en cualquier soporte o tecnología, el medio por excelencia usado por los seres humanos en la construcción de conocimiento.

- En estas prácticas educativas mediadas pedagógicamente, se utilizará el lenguaje como medio de apropiación y organización del conocimiento, desde el tema, desde el aprendizaje y desde la forma.

- En dichas metodologías y dichas prácticas, los docentes y los estudiantes interactúan a partir de mediadores, medios y mediaciones del conocimiento.

- Se entiende entonces que los mediadores son las variadas formas de relatar, de narrar, de argumentar, de escenificar, o sea las maneras de representar el saber.

- Que los medios son la voz y el cuerpo como el primer medio de comunicación audiovisual que poseemos los educadores y los estudiantes, además del libro, el tablero, el 
cuaderno de notas, el periódico, las revistas, la fotografía, el cartel, el comic, el cine, la radio, la televisión, el video y la imagen en general.

- Que las mediaciones son estructurales y cognitivas, técnicas y culturales, y el docente debe tener presente de manera especial la mediación pedagógica.

\section{Semillero de investigación Edumedia-3}

El avance de investigación que se ha presentado en este artículo, se ha llevado a cabo al interior del semillero de investigación Edumedia-3, en ese sentido es importante aportar un breve contexto. Las premisas que se han elaborado a través del proceso de construcción e implementación del semillero y la línea de investigación son: Los semilleros se conciben como espacios de investigación formativa, es decir que son el escenario educativo en el que los estudiantes orientados por un docente tutor de diferentes semestres y programas académicos, aprenden y apropian las habilidades para la investigación propiamente dicha.

Edumedia-3 es un semillero en el que se desarrollan habilidades investigativas, a través de proyectos en los que se exploran las posibilidades educativas de los medios de comunicación, dicho de otro modo, en dicho espacio de formación investigativa se está estructurando la noción de Educación mediatizada, que en gran medida se constituye en una de las categorías teóricas y conceptuales que caracterizan a la Licenciatura en comunicación e informática educativas y que emerge de la Comunicación Educativa y del pensamiento educomunicativo contemporáneos.

El semillero Edumedia-3 como escenario de formación investigativa, aporta elementos teóricos y prácticos que contribuyen a los planes de curso de las asignaturas que hacen parte del Área de Educación y Medios, y por lo tanto al Plan de estudios. Además impacta de manera positiva las prácticas investigativas de los estudiantes, por lo tanto sus trabajos de grado. De lo anterior se configura la línea de investigación en Educación mediatizada, que articula investigación, docencia, e incluso puede generar nuevos escenarios de prácticas profesionales y proyectos de extensión a la comunidad en general.

Ahora bien, desde el segundo semestre del año 2013 y en el 2014 diseñé e implementé el proceso del semillero proponiendo tres ciclos de experiencia en la investigación formativa:

Nivel Watson (inducción a un paradigma de investigación, en este caso el indicial o teoría de los indicios),

Nivel Holmes (transición en la que los estudiantes ponen en práctica el paradigma aprendido, usando herramientas de investigación propias de las Ciencias sociales y humanas, a través de un proyecto de aplicación del conocimiento relacionado con su perfil como licenciados),

Nivel Dupin (momento en el que los estudiantes pueden liderar a otros en el proceso que vivieron desde el primer nivel, y poseen elementos que podrán usar en la formulación de su trabajo de grado).

\section{Metodología de esta investigación que se encuentra en curso}

Para explicar la metodología de esta investigación que está en desarrollo, es necesario advertir varias cosas: La investigación hace parte del desarrollo de la línea de investigación en Educación mediatizada de la Licenciatura en comunicación e informática educativa de la Universidad Tecnológica de Pereira, y surge en el contexto del semillero de investigación Edumedia-3 en el año 2013. Esta licenciatura en Colombia es un pregrado orientado a la formación de educadores en sentido estricto, es decir, profesionales de la educación que una vez graduados ingresarán a instituciones de educación formal. Y en sentido amplio, la licenciatura está orientada a formar educomunicadores que podrán investigar o educar en procesos y proyectos de alfabetización mediática, educación para los medios, comunicación educativa y usos educativos de los medios de comunicación, además de promover la ética de los medios, la recepción crítica y activa de las audiencias y la ciudadanía mediática, en procesos de educación no-formal e informal. De allí que 
este estudio nace en el contexto educativo que he enunciado, en el que la reflexión sobre los usos educativos de los medios en diversos escenarios y modalidades, ha sido permanente y desde hace más de una década.

Teniendo esto claro se puede afirmar que es en las actuales reflexiones, estudios y publicaciones sobre las relaciones entre medios y educación, cuando surge la necesidad de aplicar un conocimiento organizado en varias epistemes, que encuentran anclaje en las metodologías educativas como la educación mediatizada, o dicho de otro modo: en el proceso de mediatización del conocimiento.

Por lo tanto, la investigación a la que hago referencia desde el comienzo, ha implicado inicialmente un estudio teórico que sin ser monográfico, ha requerido de una pesquisa de la literatura relacionada con el objeto de estudio, la organización de notas, y de un archivo de naturaleza heterodoxa: que alberga libros, artículos, videos, audios, páginas web, información en redes sociales, imágenes, fotografías y gráficos, así como ha requerido de memorias personales, y observaciones de las actividades académicas de docentes y estudiantes en los procesos de mediatización.

Dichos recursos, la sistematización y la interpretación de la información han servido para establecer algunas distinciones, - por ejemplo la diferencia entre lo mediado y lo mediato, o entre la educación mediada y la educación mediatizada -, y de paso elaborar un marco conceptual que sirva de base para elaborar categorías.

Es así que en primera instancia se trata de un estudio teórico, que permite la elaboración de documentos como este, en el que se presentan resultados de la pesquisa en curso, a la vez que en el semillero de investigación Edumedia-3 y en el aula de clase, se ponen a prueba los hallazgos provisionales a través de diferentes pretextos: la puesta en escena, la exploración, los talleres de investigación formativa, conversatorios, juegos, lecturas, recolección e interpretación indicial, entre otros.

Es por ello que luego de obtener una base teórica en el año 2013, los encuentros en el año 2014 entre docentes y estudiantes al interior del semillero de investigación, se centraron en el proceso de transcreación del relato literario El hombre que perdió su sombra de Adelbert Von Chamisso (2013), editado por Rodrigo Argüello, a la puesta en escena Petersis. Viaje de un ser fragmentado, de manera tal que el aprendizaje por descubrimiento posibilitara el registro de nuevos hallazgos, registrados a través de actas de cada sesión, fotografías, videos e informes del proceso, elaborados por los estudiantes y el docente tutor. La puesta en escena multimedia del relato mencionado quedó como síntesis del aprendizaje por descubrimiento con los estudiantes, durante su vivencia en el nivel de transición (Holmes).

$\mathrm{Y}$ en este año cuatro estudiantes del semillero están realizando el informe final de dos trabajos de grado que emergieron de la puesta en escena, como analogía que les permita reflexionar elementos teóricos y prácticos de la educación mediatizada o del proceso de mediatización del conocimiento, $\mathrm{y}$ hace unos meses han ingresado al nivel Watson (iniciados), nuevos integrantes al semillero, para aprender de la experiencia adquirida por quienes están en un nivel avanzado (Dupin).

Como parte del proceso, en este momento contamos con dos ponencias en encuentros de investigadores, dos trabajos de grado (en la Licenciatura en comunicación educativa y en la Licenciatura en español y literatura), página web (http://edumedia3. co), en la que se presentan resultados del proceso investigativo, y programas de radio que sirvieron en 2014 para difundir los avances.

\section{REFERENCIAS}

ARGÜELlO, G. Rodrigo. Las proyecciones de Prometeo. Tecnologías de la información y las comunicaciones y la (trans)formación del sujeto. Bogotá D. C.: Fractalia Ediciones, 2011.

BRIGGS, Asa; BURKE, Peter. De Gutemberg a Internet. Una historia social de los medios de comunicación. España: Santillana ediciones, 2002. 
BRUNER, Jerome S. Realidad mental y mundos posibles. Los actos de la imaginación que dan sentido a la experiencia. Barcelona: Gedisa, 2010.

BRUNER, Jerome S. et al. Studies in cognitive growth. NewYork: Wiley and Sons, 1966.

BRUNER, Jerome S.; OLSON, David R. Aprendizaje por experiencia directa y aprendizaje por experiencia mediatizada. Madrid: UNESCO, 1973.

DAWKINS, Richard. EI gen egoista. Las bases biológicas de nuestra consulta. 15. ed. Barcelona: Salvat, 2002.

DE MORAES, Denis (Coord.). Sociedad mediatizada. Barcelona: Gedisa, 2007.

DUCH, Lluís; CHILLÓN, Albert. Un ser de mediaciones. Antropología de la comunicación. Barcelona: Herder, 2012.

ECO, Umberto. Tratado de semiótica general. México D.F.: Ramdon House Mondadori, 2010.

FREIRE, Paulo. Pedagogía del oprimido. México: Siglo XXI editores, 2008.

Pedagogia do oprimido. Rio de Janeiro: Paz e Terra, 2014.

GOFFMAN, Erving. La presentación de la persona en la vida cotidiana. Argentina: Amorrortu, 2009.

GUTIÉRREZ Pérez; Francisco; PRIETO Castillo, Daniel. La mediación pedagógica. Buenos Aires: La Crujía Ediciones, 2007.

KAPLÚN, Mario. Una pedagogía de la comunicación. En: APARICI, Roberto. et al. Educomunicación: más allá del 2.0. Barcelona: Gedisa, 2010. p. 41-61.

MARTÍN Serrano, Manuel. La mediación social. Madrid: Akal, 2008.

La producción social de comunicación. Madrid: Alianza Editorial, 2009.

PINKER, Steven. EI mundo de las palabras. Una introducción a la naturaleza humana. Barcelona: Paidós, 2007.

REAL ACADEMIA ESPAÑOLA (RAE). Diccionario de la lengua española. Mediatizar. Madrid, 2015a. Disponoble: $<$ http://dle.rae.es/?w=mediatizar\&m=form\&o=h $>$. Recuperado el: 05 abr. 2015.

Diccionario de la lengua española. Mediato. Madrid, 2015b. Disponoble: $<\mathrm{http}: / /$ dle.rae. $\mathrm{es} / \mathrm{T} \mathrm{w}=$ mediato\&m$=$ form\&o $=\mathrm{h}>$. Recuperado el: 05 abr. 2015.

SARASON, Seymour B. La enseñanza como arte de representación. Buenos Aires: Amorrortu, 2002.

THOMPSON, John B. Los media y la modernidad. Una teoría de los medios de comunicación. Buenos Aires: Paidós, 1998.

Ideología y cultura moderna. Teoría crítica social en la era de la comunicación de masas. México D.F.: Universidad Autónoma Metropolitana, 2002.

VERÓN, Eliseo. Interfaces. Sobre la democracia audiovisual evolucionada. En: FERRY, Jean-Marc. et al. EI nuevo espacio público. Barcelona: Gedisa, 1998. p. 124-126.

El cuerpo de las imágenes. Bogotá D. C.: Editorial Norma, 2001.

La semiosis social. Barcelona: Gedisa, 2014.

VON CHAMISSO, Adelbert. El hombre que perdió su sombra. O la maravillosa historia de Peter Schelemil. Bogotá: NET educative, 2013.

VYGOTSKY, Lev. S. Thought and language. Cambridge, MS: The MIT Press, 1962.

Recebido em: 30.07 .2015

Aprovado em: 09.10.2015 